\title{
DELIMITAÇÃO DA ZONA RIPÁRIA EM UMA MICROBACIA
}

\author{
Maria José Brito Zakia - Escola de Engenharia de São Carlos - EESC/USP - São Carlos/SP, Fernando Frosini \\ Barros Ferraz - ESALQ/USP - São Paulo/SP, Antonio Marozzi Righetto - EESC/USP - São Carlos/SP, \\ Walter de Paula Lima - ESALQ - USP - Piracicaba/SP
}

\section{INTRODUÇÃO}

As zonas ripárias constituem parte importante da microbacia, tanto do ponto de vista estético como ecológico, em termos de biodiversidade, e principalmente hidrológico. Elas se caracterizam pela condição de saturação decorrente da superficialidade do lençol freático na maior parte do ano, de modo que há predomínio de espécies tipicamente adaptadas a essas condições edáficas.

Dessa forma, do ponto de vista da conservação da saúde da microbacia e consequentemente dos recursos hídricos, parece lógico concluir que a delimitação da zona ripária é o primeiro passo fundamental. Essa delimitação pode ser aferida por métodos expeditos, como pela presença de vegetação característica de áreas saturadas ou pela cor e tipo de solo.

O objetivo deste capítulo é apresentar uma metodologia de fácil aplicação para a identificação da zona ripária de uma microbacia experimental e que possa ser empregada no planejamento do uso do solo.

\section{FUNDAMENTOS}

Pode-se definir gestão ambiental como tentativa de: a) avaliar valores-limite das perturbações e alterações que, uma vez excedidos, resultam em recuperação bastante demorada do meio ambiente e b) manter os ecossistemas dentro de suas zonas de resiliência, de modo a maximizar a recuperação dos recursos do ecossistema natural em favor do homem, assegurando sua produtividade prolongada. Por sua vez, resiliência é a capacidade de um ecossistema retornar a seu estado de equilíbrio dinâmico após sofrer alteração ou agressão.

Uma área ripária é um écotono tridimensional com interações que incluem os ecossistemas aquáticos e terrestres, os quais se estendem desde o lençol freático, passando pelas copas das árvores e pelas planícies de inundação até as encostas por onde a água é drenada. Talvez mais do que qualquer outra característica da paisagem, as áreas ripárias focam o conceito de paisagem nas conexões entre as comunidades de peixes e outros animais nas interações entre sítio e regeneração florestal e entre economia e recreação. Cada uma das áreas de interesse (madeira, água e fauna, recreação, agricultura, transporte) tem razões para definir suas percepções de manejo interdisciplinar em uma estrutura de paisagem, que apresenta diferentes atores e responsáveis. É nessa abordagem de paisagem que o direito de propriedade e a responsabilidade comunitária testam os limites entre o direito privado e o direito do Estado.

As zonas ripárias podem ser entendidas como as zonas saturadas que margeiam os cursos d'água e suas cabeceiras e que podem se expandir durante chuvas prolongadas. O termo área ripária ou ciliar tem sido utilizado tanto para caracterizar a porção do terreno que inclui a ribanceira do rio como a planície de inundação, com suas condições edáficas próprias e a vegetação que aí ocorre, a mata ciliar ou mata ripária. 


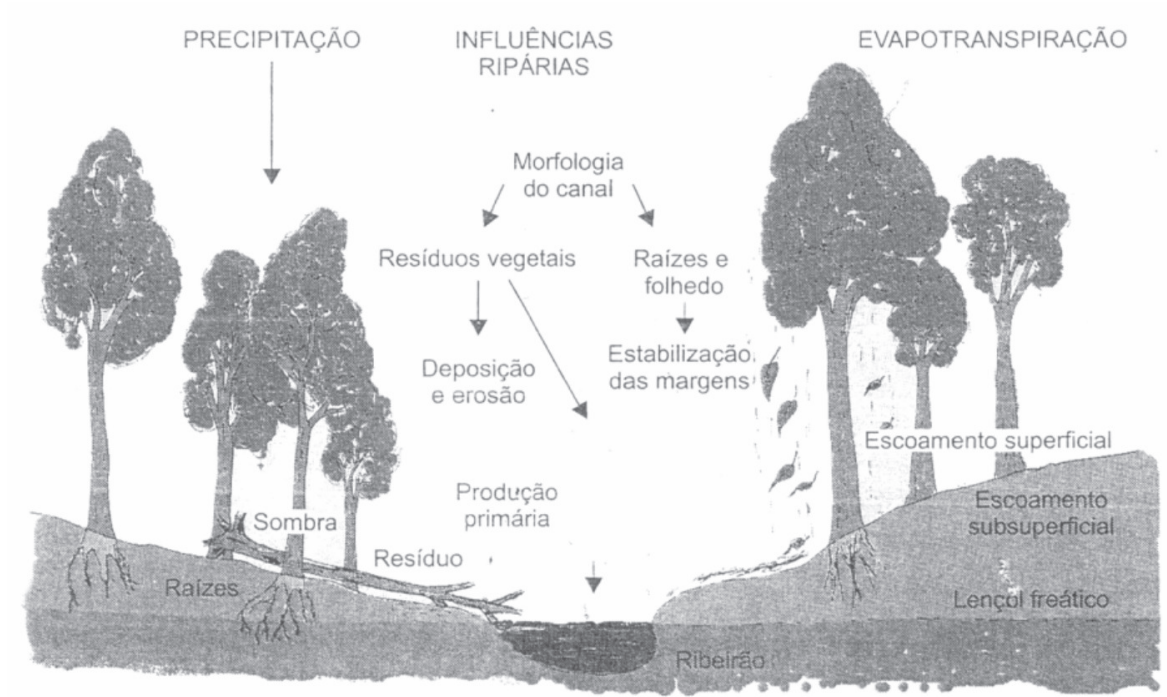

Figura 1. Esquema conceitual de uma zona ripária (modificado a partir de Likens, 1992).

Em trabalho, de revisão sobre hidrologia de matas ciliares, Lima (1989) destaca que nas áreas com boas condições de cobertura vegetal a ocorrência de escoamento superficial hortoniano ao longo de todas as partes da microbiologia é rara ou mesmo ausente. Por outro lado, algumas áreas parciais podem produzir escoamento superficial mesmo quando a intensidade da chuva é inferior à capacidade de infiltração média para a microbacia como um todo.

Essas áreas são:

a) zonas saturadas que margeiam os cursos d'água e suas cabeceiras, as quais podem se expandir durante chuvas prolongadas (zonas ripárias);

b) concavidades do terreno para as quais convergem as linhas de fluxo, como as frequentemente existentes nas cabeceiras (também parte da zona ripária);

c) áreas de solo raso, com baixa capacidade de infiltração.

Nas situações (a) e (b), o processo é denominado de "escoamento superficial de áreas saturadas" e ocorre mesmo que a intensidade da chuva seja inferior à capacidade de infiltração do solo. Parte desse processo pode ocorrer na forma de interfluxo lateral e, portanto, não se trata de escoamento hortoniano (Chorley, 1978).

Dessa forma, considerando microbacias onde o uso da terra não tenha provocado o aparecimento de áreas compactadas ou impermeáveis, nas quais poderia ocorrer escoamento superficial hortoniano durante as chuvas, as zonas ripárias desempenham papel hidrológico fundamental na geração do escoamento direto. Nas áreas saturadas da microbacia, tanto ao longo das margens da rede de drenagem quanto nas cabeceiras, e até mesmo em manchas de áreas saturadas que podem ser encontradas até nos locais mais elevados da encosta, o que prevalece é o escoamento superficial de áreas saturadas. Essa relação hidrológica na escala da microbacia caracteriza a importância das áreas ripárias e reforça a necessidade de sua identificação e delimitação (Lima, 2003).

\section{Estudo de caso: a Microbacia da Onça}

Este estudo de caso foi desenvolvido na fazenda São Nicolau, município de Arapoti, Estado do Paraná, Brasil, em área pertencente à Indústria de Papel e Celulose Arapoti S/A (INPACEL). De acordo com a classificação de Köppen, o clima na região é de transição entre os tipos Cfa, que é mesotérmico sem estação seca e com verões quentes, e $\mathrm{Cfb}$, que também é mesotérmico entre úmido e subúmido, sem estação seca, mas com verões frescos. As temperaturas médias anuais entre 1984 e 1993 indicam que o período de novembro a março é 
o mais quente, com temperaturas médias entre 22,3 e $23,6^{\circ} \mathrm{C}$. As temperaturas mais baixas registradas variam de 2 a $13^{\circ} \mathrm{C}$, com destaque para o período de julho a agosto, com temperaturas mínimas entre $2 \mathrm{e} 3^{\circ} \mathrm{C}$.

Para o desenvolvimento dos trabalhos foi selecionada uma microbacia hidrográfica de 62 ha localizada na área de reserva florestal (reserva Matão) da fazenda São Nicolau. Nela, denominada microbacia experimental da Onça, foi instalada uma estação linimétrica (vertedor e limnígrafo) para contínua medição do deflúvio. Também foram demarcado três transectos transversais ao curso d'água para estudos da vegetação. A Tabela 1 contém as principais características morfométricas da bacia da Onça. É importante salientar que o presente estudo de caso é parte de um trabalho mais abrangente (Zakia, 1998), no qual a identificação da zona ripária foi confrontada e aferida com a produção de água na bacia e com a presença de espécies indicadoras de áreas úmidas (Gandara et al.,1996). Todavia, este trabalho teve por objetivo a descrição da metodologia utilizada para a identificação da zona ripária, sem entrar em detalhes quanto aos estudos envolvendo a simulação da vazão e a vegetação.

Os principais critérios adotados para a escolha da microbacia experimental forma: (a) área mínima de 50 ha, para permitir os estudos propostos para a vegetação, (b) acesso que possibilite a construção de vertedores e a leitura de instrumentos pelo menos a cada 15 dias e (c) área com vegetação nativa com baixo grau de perturbação.
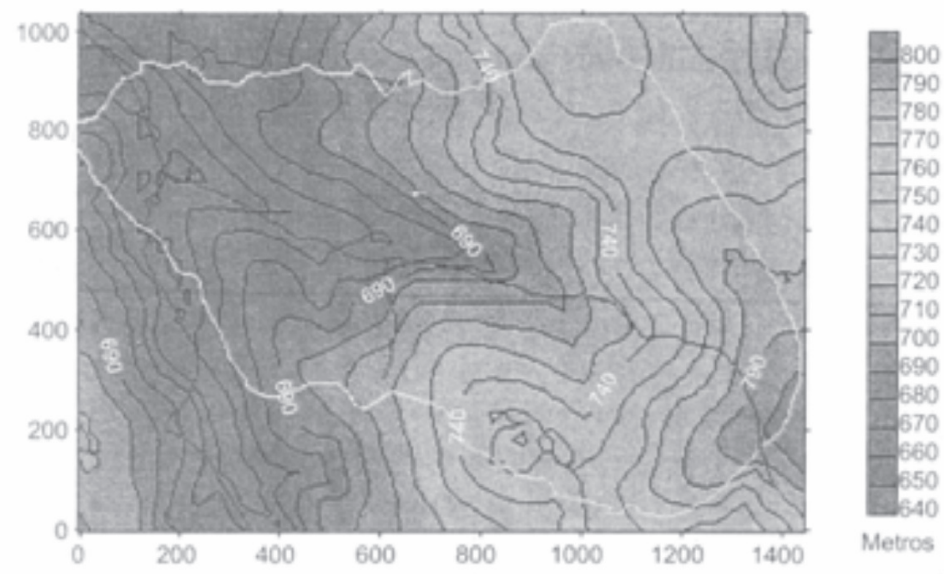

Figura 2. Planta planialtimétrica da área de estudo e a delimitação da microbacia experimental da Onça.

\begin{tabular}{|l|c|}
\hline \multicolumn{2}{|c|}{ Característica } \\
\hline Área (A) & $62 \mathrm{ha}$ \\
\hline Perímetro (P) & $3.400 \mathrm{~m}$ \\
\hline Ordem & 2 \\
\hline Comprimento do canal principal (L) & $1.200 \mathrm{~m}$ \\
\hline Comprimento do eico principal (Le) & $1.250 \mathrm{~m}$ \\
\hline Comprimento total dos canais (Lt) & $1.730 \mathrm{~m}$ \\
\hline Densidade de drenagem (DD) & $3 \mathrm{~km} / \mathrm{km}^{2}$ \\
\hline Forma da bacia (FF) & 0,37 \\
\hline Índice de circularidade (IC) & 0,63 \\
\hline Declividade média (\%) & $18,3 \%$ \\
\hline Orientação & $\mathrm{NO}$ \\
\hline
\end{tabular}

Tabela 1. Caracterização morfométrica da microbacia da Onça. 
Identificação da área variável de afluência (Zona Ripária) com utilização do TOPMODEL

\section{Conceituação e Fundamentação Teórica do TOPMODEL}

O TopModel é definido pelos próprios autores (Beven et al., 1995) como uma coleção de conceitos que pode ser usada em condições apropriadas, não é e não pretende ser um modelo fechado, sob a forma de "pacote". Este modelo reproduz o comportamento hidrológico de microbacias, em particular da dinâmica das áreas de contribuição. Embora muitos autores descrevam-no como um modelo de base física, parece estar claro que se trata de um modelo antes de tudo conceitual (Franchini et al., 1996).

Em sua fundamentação teórica, o TopModel envolve uma sequência de simplificações, assumindo quatro premissas básicas preparadas a partir de Beven et al. (1995), Franchini et al. (1996) e Zakia (1998):

Premissa 1: a dinâmica das zonas saturadas pode ser estimada por sucessivos estados permanentes (steady-state);

Premissa 2: o gradiente hidráulico do escoamento superficial na zona saturada pode ser estimado pela declividade local do terreno (tan $\beta$ ). Isso só será válido caso a microbacia esteja adequadamente discretizada, ou seja, tenha sido estabelecido um modelo digital do terreno com um grid adequado;

Premissa 3: a distribuição da transmissividade da água na solo é função exponencial do déficit de armazenamento de água ao longo do perfil do solo até alcançar a superfície freática, onde impera a condição de saturação.

A transmissividade saturada do solo (T(0)) é o produto da condutividade hidráulica saturada $(\mathbf{K}(\mathbf{0}))$ do solo pela profundidade do solo saturado.
A partir das três premissas pode-se expressar a vazão subsuperficial em um ponto, ou seja, em uma célula " $\mathbf{i}$ " da bacia, como segue:

$$
\operatorname{qsub}_{\mathrm{i}}=\mathbf{T}(\boldsymbol{\theta}) \cdot \tan \beta_{\mathrm{i}}
$$

Sendo:

$\mathbf{T}(\boldsymbol{\theta})$ = transmissividade da água no solo $\left(\mathrm{m}^{2} / \mathrm{h}\right)$;

$\tan \boldsymbol{\beta}_{i}=$ inclinação do terreno na célula i;

Mas a transmissividade, de acordo com a Premissa 3, pode ser expressa por:

$$
\mathbf{T}(\boldsymbol{\theta})=\mathbf{T}(\mathbf{0}) \cdot \mathrm{e}^{-} \boldsymbol{\Delta}^{\mathrm{s} / \mathrm{m}}
$$

Sendo:

$\mathbf{T}(\mathbf{0})=$ transmissividade lateral em condições de saturação $\left(\mathrm{m}^{2} / \mathrm{h}\right)$

$\Delta \boldsymbol{S}=$ variação de armazenamento de água no solo

$\boldsymbol{m}=$ parâmetro de ajuste do modelo representando o fator de redução da curva exponencial. Quanto maior “ $\mathrm{m}$ ”, menor a diminuição de “ $\mathbf{T}$ ” com o déficit de armazenamento.

Para entender melhor o termo déficit de armazenamento de água no solo é preciso lembrar que há três teores de umidade do solo utilizados com referência:

-Umidade de saturação ( $\boldsymbol{\theta} \boldsymbol{s} \boldsymbol{a t})$ : ocorre quando todos os poros, tanto macro como micros, estão preenchidos com água;

-Umidade do solo em condições de capacidade de campo $(\boldsymbol{\theta} \boldsymbol{c c})$ : ocorre quando todos os microporos estão preenchidos com água $\left(\mathrm{cm}^{3} / \mathrm{cm}^{3}\right)$;

-Umidade do solo em condições de murcha permanente $(\boldsymbol{\theta} \boldsymbol{p m p})$ : quando a água está retida no solo com tensões maiores do que as plantas conseguem retirar $\left(\mathrm{cm}^{3} / \mathrm{cm}^{3}\right)$.

Assim, a partir desses três teores têm-se os seguintes déficits de armazenamento de água de referência:

$$
\Delta S=(\boldsymbol{\theta s a t}-\boldsymbol{\theta c c}) \cdot \mathbf{z}-\text { água gravitacional }
$$


$\Delta \mathbf{S}=(\boldsymbol{\theta c c}-\boldsymbol{\theta p m p}) \cdot \mathbf{z}-$ água disponível para as plantas, sendo $\mathrm{z}$ a profundidade do solo na zona das raízes $(\mathrm{m})$.

Substituindo “ $\Delta \boldsymbol{S}$ ” na equação (2) por $(\boldsymbol{\Delta} \boldsymbol{\theta} \cdot \boldsymbol{z})$ tem-se:

$$
\mathbf{T}(\boldsymbol{\theta})=\mathbf{T}(\mathbf{0}) \mathrm{e}^{-}
$$

E denominado como " $f$ " tem-se:

$\mathbf{T}(\boldsymbol{\theta})=\mathbf{T}(\mathbf{0}) \cdot \mathrm{e}^{-\mathrm{f} \cdot \mathrm{z}}$

Substituindo T( $\boldsymbol{\theta}$ ) da equação (1) pela equação (4) tem-se para cada ponto “ $\mathbf{i}$ " a vazão superficial:

$$
\mathrm{qsub}_{\mathrm{i}}=\mathbf{T}(0)_{\mathrm{i}} \cdot \mathrm{e}^{-\mathrm{f.z} . \mathrm{i}} \cdot \tan \beta_{\mathrm{i}}
$$

Até aqui as premissas foram aplicadas a cada célula, ou seja, para cada ponto i da bacia. Porém, cada uma dessas células ou pontos tem uma área de contribuição, ou seja, uma pequena área da microbacia hidrográfica que drena para elas. Surge então a $4^{\mathrm{a}}$ premissa, que relaciona $q s u b_{i}$ com a área de contribuição $\mathrm{ac}_{\mathrm{i}}$ :

Premissa 4: a vazão superficial - qsub $b_{i}-\dot{e} o$ proporcional ao produto da recarga (r) para a zona saturada pela área de contribuição ao ponto i $\left(a c_{i}\right)$.

Ou seja:

$$
q s u b_{i}=\alpha r^{*} \cdot a c_{i}
$$

Sendo:

$\boldsymbol{r}^{*}=$ a recarga considerada uniforme em toda $\boldsymbol{a c} c_{i}$ $(\mathrm{m} / \mathrm{h})$

Chamando a recarga efetiva $\boldsymbol{r}=\boldsymbol{\alpha} \boldsymbol{r} *$ tem-se que:

$q s u b_{i}=r \cdot a c_{i}$
Resultam, portanto, duas expressões, equação (5) e equação (7) para $q s u b_{i}$, igualando-as obtém-se que:

$T(0)_{i} \cdot e^{-f . z} \cdot \tan \beta_{i}=r \cdot a c_{i}$

ou, explicitando $z_{i}$ :

$\mathrm{z}_{\mathrm{i}}=-\frac{1}{\mathrm{f}}\left(\ln \mathrm{r}+\ln \frac{\mathrm{ac}_{\mathrm{i}}}{\mathrm{T}(0)_{1}}\right)$

Tem-se então uma expressão que relaciona a profundidade da superfície freática no ponto i $(\boldsymbol{z} \boldsymbol{i}) \mathrm{com}$ :

- a topografia (por meio do índice topográfico $\left.\ln \left(a c_{i} / \tan \beta_{i}\right)\right)$;

- o parâmetro f;

- a transmissividade saturada $(\mathrm{T}(0))$;

- a taxa de recarga efetiva (r).

Para toda a bacia, e não mais para cada ponto “i”, pode-se definir uma profundidade média da superfície freática:

$$
\bar{z}=1 / A \cdot \sum_{i} A_{i} \cdot z_{i}
$$

Sendo:

$\boldsymbol{A}=$ área total da bacia $\left(\mathrm{m}^{2}\right)$

$\boldsymbol{A}_{i}=$ área de cada uma das células que formam a bacia $\left(\mathrm{m}^{2}\right)$, determinada a partir do modelo digital do terreno ( $\mathrm{grid}$ ).

Substituindo a equação (9) na equação (10), obtém-se que:

$$
\bar{z}=1 / A \cdot \sum_{i} A_{i} / f \cdot\left(\ln r+1 n \frac{a c_{i}}{T(0)_{i}}\right)
$$

E subtraindo $z_{\mathrm{i}}$ de $\mathrm{z}$ obtém-se equação (12):

$$
\begin{gathered}
\bar{z}=1 / A \cdot \sum\left\{-A_{i} / f\left(\ln r+\ln \frac{a c_{i}}{T(0)_{i}}\right)\right\} \\
+ \\
\left(\ln r+\ln \frac{a c_{i}}{T(0)_{i} \cdot \tan \beta_{i}}\right)
\end{gathered}
$$


Admitindo-se duas simplificações:

- r é uniformemente distribuída em toda bacia;

- f é constante.

A equação (12) transforma-se em:

$$
\bar{z}-z_{i}=1 / A \cdot \sum_{i}\left\{-A_{i} / f\left(\ln r+1 n \frac{a c_{i}}{\tan \beta_{i}}-A_{i}\right) / f \cdot \ln T(0)\right\}+1 / f\left(\ln \frac{a c_{i}}{\tan \beta}-1 n T(0)\right)
$$

Definindo-se: $\ln T=\boldsymbol{1} / \boldsymbol{A} \cdot \boldsymbol{S} \boldsymbol{A}_{\boldsymbol{i}} \cdot \boldsymbol{l n} \boldsymbol{T}(\mathbf{0})$ então:

$$
f \cdot\left(\bar{z}-z_{i}\right)\left[\ln \frac{a c_{i}}{\tan \beta_{i}}-\lambda\right]-\left[\ln T(0)_{i}-1 n \bar{T}\right]
$$

ou, ainda, definindo-se: $\boldsymbol{g}=\boldsymbol{1}$ - $\boldsymbol{l n} \boldsymbol{T}$ obtém-se que:

$$
f \cdot\left(\bar{z}-z_{i}\right)\left[\ln \frac{a c_{i}}{\tan \beta_{i}}-1 n T(0)_{i}\right]-\gamma
$$

A partir da equação (2) e equação (3) pode-se finalmente apresentar a equação (16):

$$
f \cdot(\bar{z}-z)=\frac{\Delta S-\Delta S_{i}}{m}
$$

Todos os passos até aqui tratam das premissas básicas do modelo, as quais demonstram ser possível relacionar a topografia e o escoamento subsuperficial em condições saturadas.

Resta agora entender o modelo tanto nas condições saturadas quanto em condições não saturadas. O TopModel considera o solo, em cada ponto i, como um reservatório de água dividido em três zonas:

- Zona das raízes;

- Zona de transmissão;

- Zona saturada.

$\mathrm{Na}$ zona das raízes, a variação de armazenamento $(\boldsymbol{\Delta S})$ no período chuvoso varia entre $\boldsymbol{\theta}$ sat e $\boldsymbol{\theta c c}$, enquanto nos períodos sem chuva e em decorrência da evapotranspiração, $\Delta \mathbf{S}$ varia entre $\boldsymbol{\theta c c}$ e $\boldsymbol{\theta} \mathbf{p m p}$ (Figura 3 ).

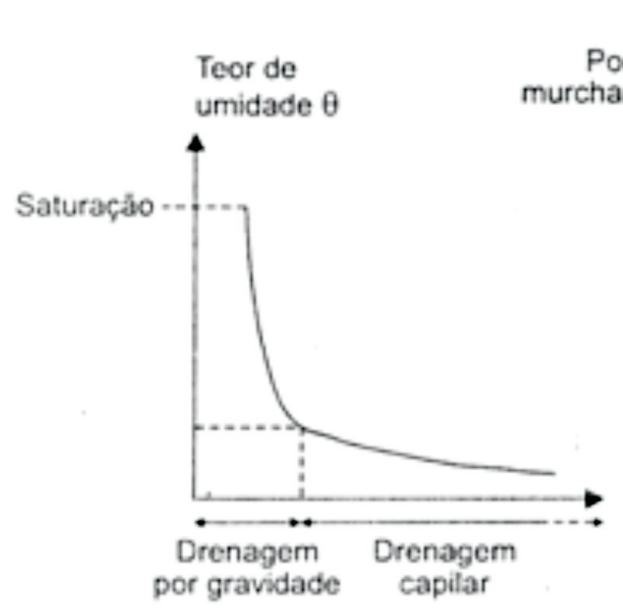

a)

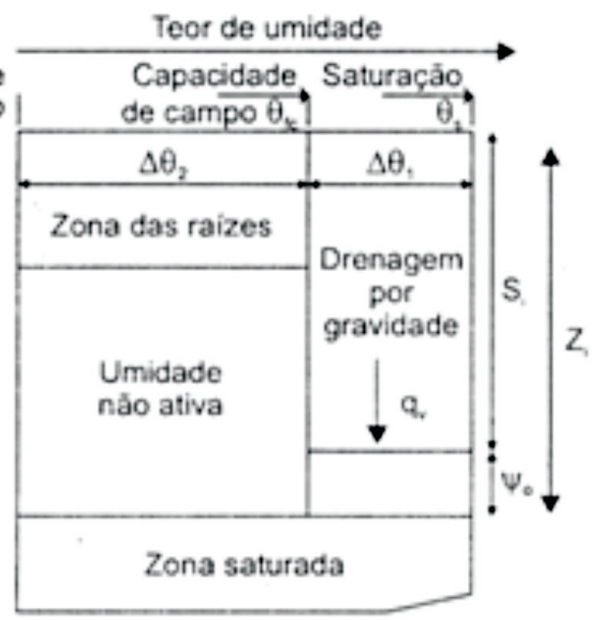

b)

Figura 3. (a) Evolução do teor de umidade em uma recessão e (b) representação esquemática da zona não saturada (Preparada por Moraes (1998) a partir de Beven et al. (1995). 
A recarga de água para a zona saturada (isto é, para o lençol freático) é avaliada pela expressão:

$$
q_{v i}=K(0)_{i} \cdot e^{-f \cdot z i}
$$

Em que $\mathrm{K}(0)$, é a condutividade hidráulica saturada do solo $(\mathrm{m} / \mathrm{h})$ no ponto $\mathbf{i}$.

Considerando-se toda a bacia, a alimentação de água para o lençol freático é:

$$
Q_{v}=\sum_{i} A_{i} \cdot \boldsymbol{q}_{v i}
$$

A saída da água da bacia a partir do lençol freático, denominada de escoamento base, é calculada pela soma das vazões de saída das células adjacentes ao curso d'água e pode ser expressa por:

$$
q b=\bar{A} \cdot e^{-} \gamma \cdot e^{-f \cdot z}
$$

Dessa forma, os mecanismos de geração de deflúvio em uma encosta ficam reduzidos a quatro processos, conforme mostra a Figura 4, o que torna evidente as simplificações adotadas.1

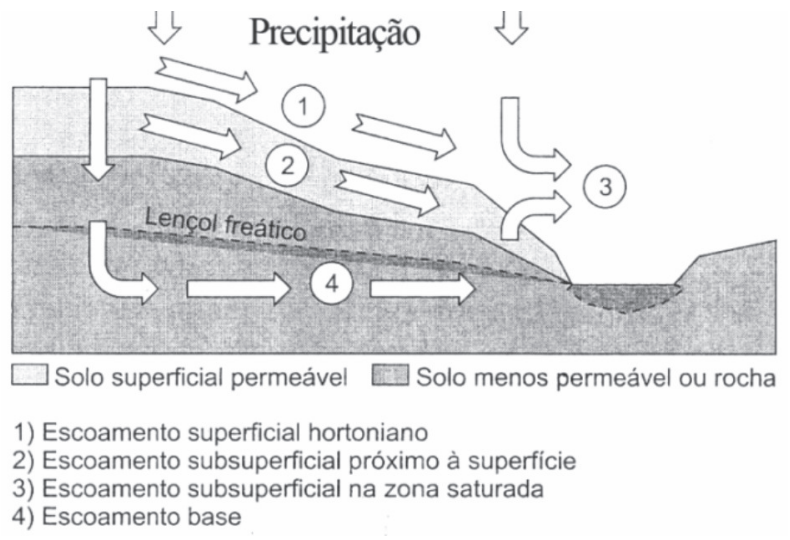

Figura 4. Os quatro processos do mecanismo de geração de deflúvio (Moraes, 1998).

A Figura 5 apresenta o esquema adotado para a microbacia hidrográfica e para a encosta do ponto de vista do uso do TopModel.

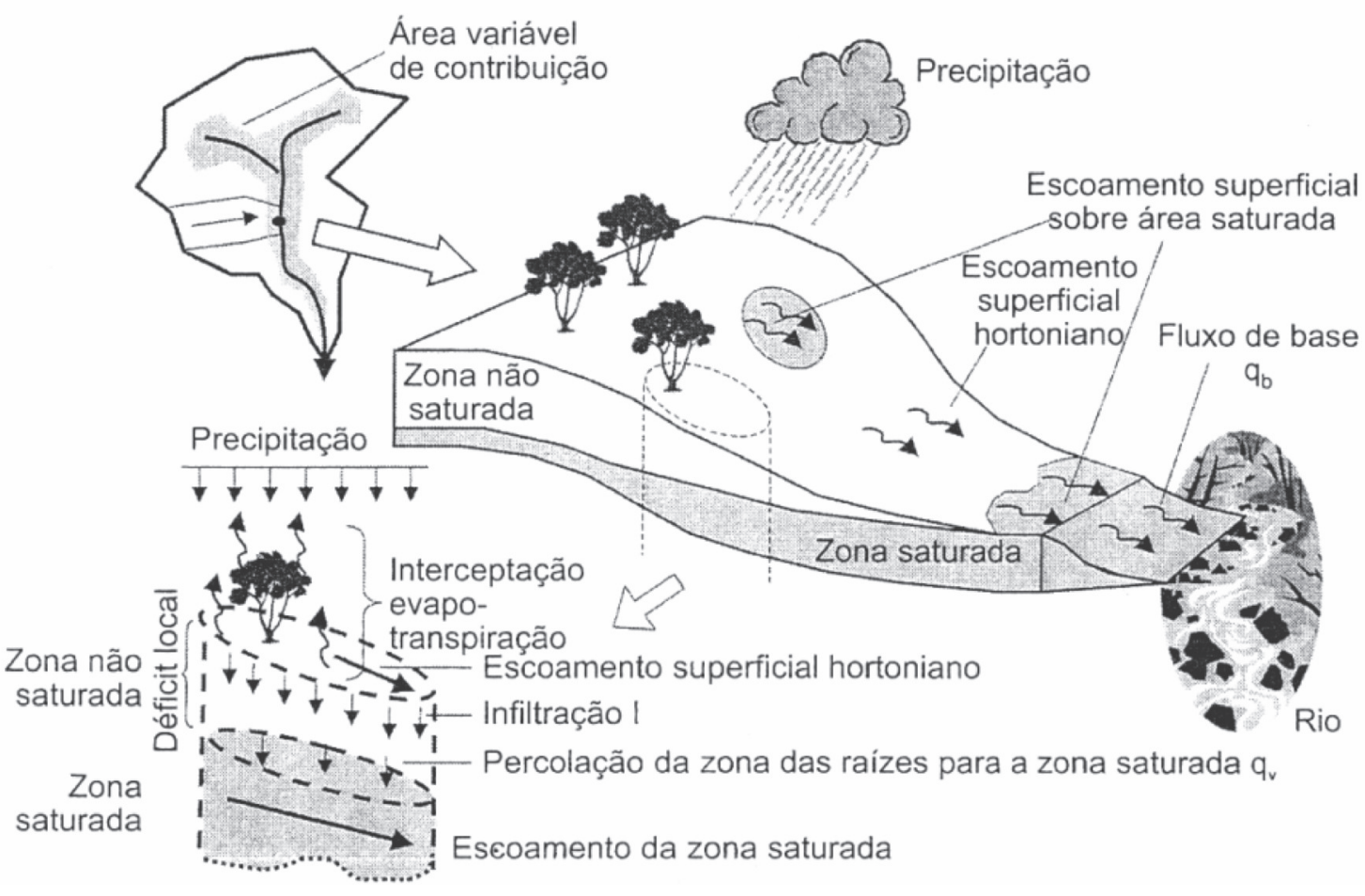

Figura 5. Esquema de uma microbacia hidrográfica no TopModel (Preparado por Moraes, 1998, a partir de Saulnier, 1996). 


\section{Preparo do Modelo Digital do Terreno e Cálculo do Î́ndice Topográfico (IT) e das Áreas de Contribuição $\left(\mathrm{ac}_{\mathrm{i}}\right)$}

O modelo digital do terreno (MDT) foi preparado no ArcView e os valores numéricos de altitude foram os dados de entrada para o programa AVA.exe, que foi compilado a partir do fonte GRIDATB.for (em linguagem Fortran e acompanhado o TopModel), o qual foi modificado, permitindo a entrada de maior número de dados e com saída compatível com os SIGs IDRISI e o ArcView GIS 3.0.

Deve-se destacar que o TopModel é um programa de simulação de vazão que utiliza a identificação das áreas variáveis de afluência. Dessa forma, tornou-se necessário trabalhar separadamente a rotina de identificação da área de contribuição - da qual se pode identificar a zona ripária - da rotina de simulação de vazão.

A primeira variável que surge para a utilização do TopModel (e também do AVA.exe) é a definição do grid, ou seja, do número de linhas e colunas que formarão a imagem RASTER, sendo recomendável uma resolução de no máximo 50 x 50 m, (Quinn et al., 1995). O dado de entrada para o AVA.exe é a plana altimétrica transformada em modelo numérico do terreno. Escolhido o grid, que no caso foi $5 \times 5 \mathrm{~m}$, e criado o modelo numérico do terreno, foi gerado, por meio do programa AVA.exe, um novo arquivo para a bacia, agora com os valores de IT em vez da altitude.

O IT foi calculado utilizando o algoritmo apresentado por Quinn et al. (1995), que envolve o raciocínio de que para cada célula há oito possíveis direções de fluxo, conforme apresenta o esquema da Figura 6a, em que a célula central pode receber fluxo, de oito diferentes células, alem da água que cai nela mesma. Cada uma dessas "rotas" é testada a partir da declividade. Assim, dado o MDT de uma área, é possível determinar a direção que a água assumirá para cada célula, gerando-se um grid de direções de fluxo (Figura 6b). Os canais são identificados como linhas de células cuja acumulação de fluxo excede um número específico de células (Figura 6c). Computando o número de células acima de uma célula qualquer na rede de drenagem, determina-se o fluxo acumulado naquela célula (Figura 6d).

Postula-se que a área de contribuição está relacionada à direção e ao comprimento do fluxo, o qual é igual a 50\% do comprimento da célula para as direções cardinais e a 35\% para as diagonais.

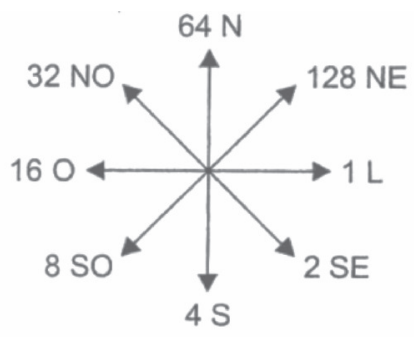

a) Modelo de fluxo

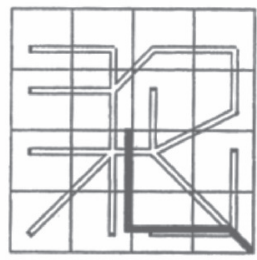

c) Rede de drenagem

\begin{tabular}{|r|r|r|r|}
\hline 1 & 4 & 8 & 16 \\
\hline 1 & 4 & 4 & 8 \\
\hline 1 & 1 & 2 & 4 \\
\hline 128 & 64 & 1 & $?$ \\
\hline
\end{tabular}

b) Direção de fluxo

\begin{tabular}{|c|c|c|c|}
\hline 0 & 1 & 1 & 0 \\
\hline 0 & 5 & 0 & 0 \\
\hline 0 & 9 & 12 & 0 \\
\hline 0 & 0 & 0 & 15 \\
\hline
\end{tabular}

d) Fluxo acumulado
Figura 6. Diagramas esquemáticos: a) do modelo de ponto d'água em oito direções, b) de uma imagem de direção de fluxo, c) da determinação da rede de drenagem e d) da acumulação de fluxo.

A partir desse procedimento, foram obtidos dois resultados: o índice topográfico para cada célula, dividido em 30 classes de frequência e que pode ser utilizado na rotina de simulação de vazão, e a área de contribuição de cada célula, a partir da qual se identifica a zona ripária. A Figura 7 apresenta um diagrama com as principais operações envolvidas no desenvolvimento da metodologia. 


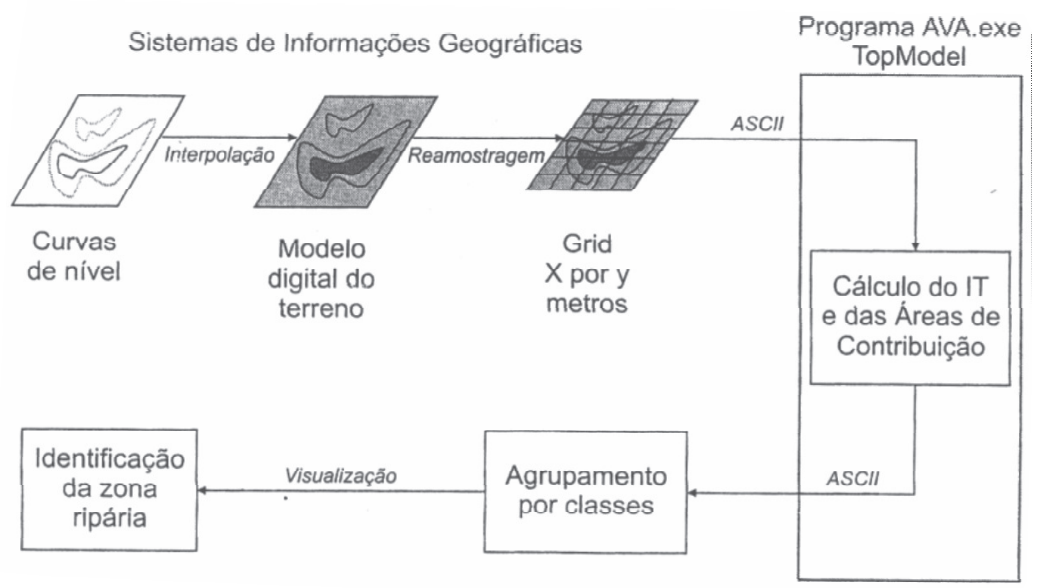

Figura 7. Diagrama esquemático da metodologia utilizada para identificação da zona ripária.

\section{RESULTADOS E DISCUSSÃO}

A Figura 8 apresenta uma imagem com os índices topográficos calculados para a microbacia e a Figura 9, as diferentes classes de contribuição. A Tabela 2 exibe os resultados numéricos obtidos na modelagem da zona ripária, em que se observa a área de contribuição para as células discretizadas e a zona a que pertencem, numa classificação em 3 classes: zona ripária, intermediária e alta

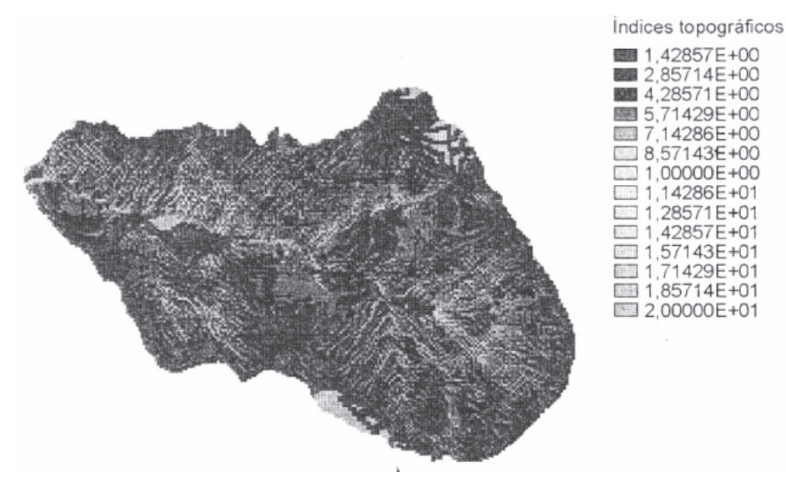

Figura 8. Imagem com os índices topográficos gerados para a microbacia da Onça.

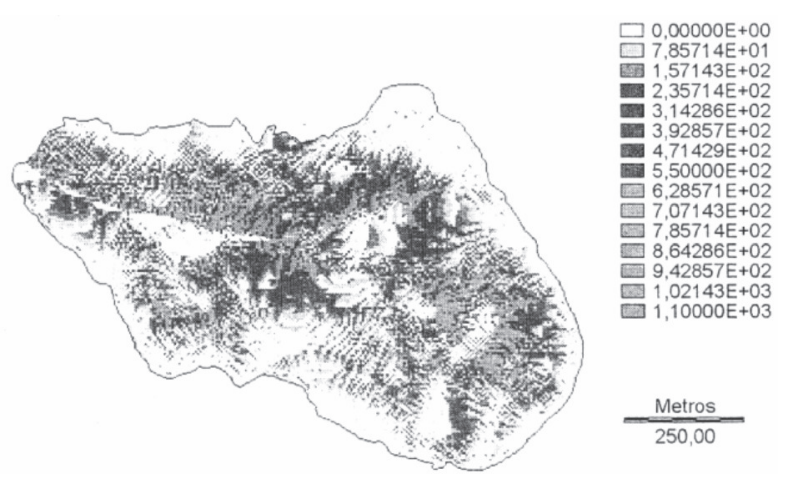

Figura 9. Classes de áreas de contribuição $\left(\mathrm{m}^{2}\right)$ da microbacia da Onça.

Tabela 2. Resultados numéricos obtidos na modelagem e na classificação das áreas de contribuição da microbacia da Onça.

\begin{tabular}{|l|c|}
\hline \multicolumn{1}{|c|}{$\mathbf{A}_{\mathbf{c}}\left(\mathbf{m}^{\mathbf{2}}\right)$} & Zona \\
\hline entre 628 e 1.100 & Zona ripária \\
\hline entre 235 e 628 & Intermediária \\
\hline entre 0 e 235 & Alta \\
\hline
\end{tabular}




\section{Comparação entre a Zona Ripária Modelada e a Área de Preservação Permanente Estipulada pela Legislação Vigente}

Comparou-se o resultado encontrado para a zona ripária com as exigências do Código Florestal Brasileiro (Lei 4771/65 modificada pela Medida Provisória 2166-67). Essa comparação é apresentada de forma gráfica na Figura 10. Em termos quantitativos, as áreas ocupadas pela APP (6,8 ha) e pela zona ripária $(6,2$ ha) são semelhantes. Todavia, enquanto o Código Florestal exige uma faixa de preservação ao longo dos cursos d'água, as áreas realmente importantes para a proteção das microbacias e dos recursos hídricos se encontram agrupadas de maneira diferente.

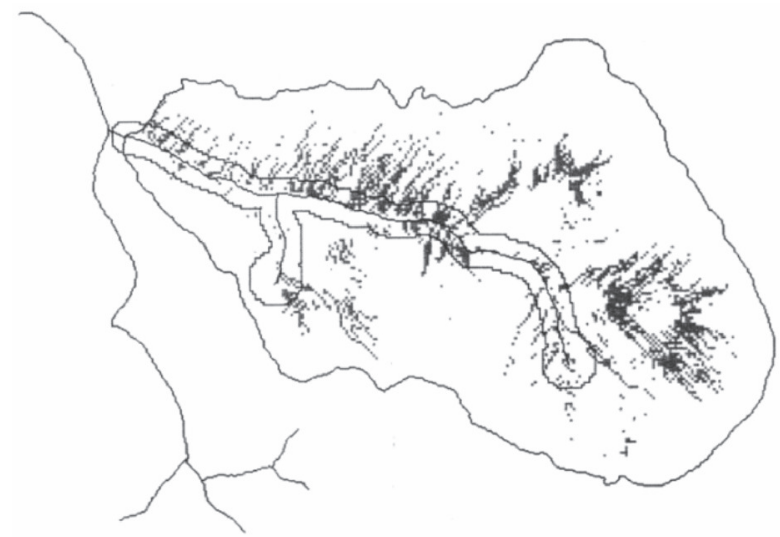

Figura 10. Comparação entre a modelagem da zona ripária (áreas hachuradas) e a delimitação da Área de Preservação Permanente (linha que demarca os $30 \mathrm{~m}$ em ambas as margens da rede hidrográfica) exigida pelo código florestal.

Os canais intermitentes são importantes na geração do escoamento direto em uma microbacia e a sua proteção é imprescindível para a manutenção de sua saúde. No entanto, não se sugere modificar a lei, que é bastante adequada para a proteção dos cursos d'água, mas vale a pena iniciar uma discussão sobre as bases técnicas das normas florestais vigentes. Esses conhecimentos devem ser incorporados ao manejo de bacias hidrográficas e ao monitoramento ambiental de microbacias.
Uma microbacia pode ter sua zona ripária identificada e se ela não puder ser incorporada a uma APP deve no mínimo ser submetida a uso especial.

Atualmente, diversos SIGs disponíveis no mercado dispõem de algoritmos com rotinas hidrológicas, como as que geram a direção de fluxo e o fluxo d'água acumulado, permitindo a simulação da rede de canais existente na microbacia. A dificuldade está em determinar corretamente a área mínima de contribuição para surgimento de um canal e quais deles são os intermitentes. A Figura 11 apresenta um fluxo d'água acumulado no qual se observa a disposição semelhante dos canais com a zona ripária modelada, que pode ser identificada pela maior densidade de canais simulados. Dessa forma, nos casos em que a modelagem da zona ripária seja tecnicamente inviável, é possível lançar mão de uma aproximação utilizando rotinas preexistentes.

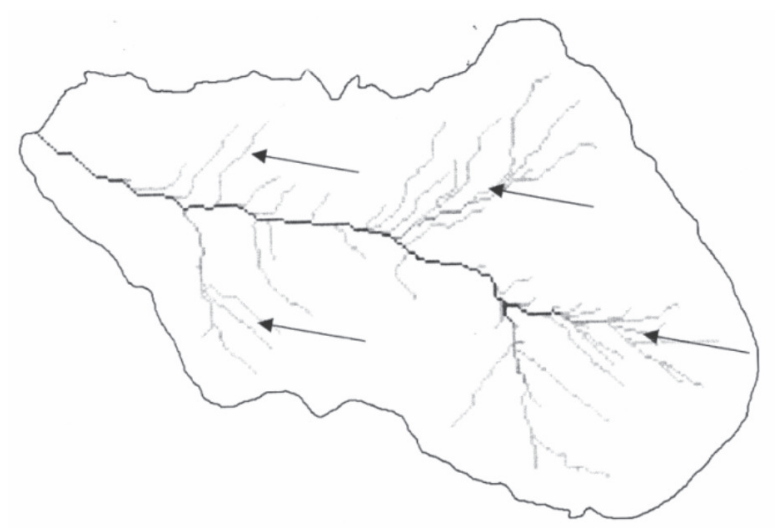

Figura 11. Imagem do acúmulo de fluxo d'água na bacia estudada que permite a identificação da zona ripária pela maior densidade de canais simulados.

\section{CONCLUSÃO}

A zona ripária pode ser identificada a partir do modelo de elevação do terreno se o escoamento direto da bacia for predominantemente representado pelo escoamento subsuperficial. Na microbacia em estudo, a zona ripária representou $10,4 \%$ de sua área, valor muito próximo da APP prevista em lei $(11 \%)$. 
A não coincidência entre a zona ripária e a APP prevista não deve (e não pode) ser vista como uma necessidade de mudar a lei, mas sim, como um início para discutir as bases técnicas da legislação florestal em vigor. A identificação da zona ripária deve ser encarada com um requisito básico para o manejo sustentável, ou seja, para a manutenção da saúde da microbacia. Nesse sentido, uma vez delimitada a área ripária da microbacia, esta, idealmente, deveria ser a área protegida pela vegetação ripária. Se isso for inviável, a delimitação da zona ripária permite pelo menos a classificação de zonas diferenciadas de manejo, o que já significa um avanço na busca do manejo sustentável.

\section{BIBLIOGRAFIA}

BEVEN, K.J. et al. User's guide to the distribuions versions. CRES Technical Report TR 110. 2.ed. Lancaster University, 1995.p.26.

CHORLEY, R.J. The hillslope hydrological cycle. In: KIRBY, M.J. (Ed.). Hillslope Hydrology.John Wiley and Sons, 1978. p.26.

FRANCHINI,M.; WENDLING,J.; OBLED,C.; TODINI,E. Physical interpretation and sensivity analysis os TOPMODEL. Journal of Hydrology, v. 175, p. 293-338, 1996.

GANDARA, F.B.; ZAKIA,M.J.B.; KAGEYAMA,P.Y.;LIMA,W.P.;CESARE,C. G. Padrões de distribuição espacial de espécies arbóreas em relação ao curso d'água em sua microbacias, em Arapoti, Para ná. In : I N T E R N AT I O N A L SYMPOSIUM ON ASSESSMENT AND MONITORY OF FORESTS IN TROPICAL DRY REGIONS WITH REFERENCE TO GALLERY FORESTS. Abstracts, 1996. p.19.

HORTON, R.E. An approach toward a physical interpretation os infiltration capacity. Soil Science Society of America
Proc, v.4, p.399-417, 1940.

LIKENS, G.E. The ecosystem approach: its use and abuse. In: KINE, O. (Ed.). Excellence in Ecology. Book 3, 1992. $165 \mathrm{p}$.

LIMA, W.P. Função hidrológica da mata ciliar. In: BARBOSA, L.M. (Ed.). SIMPÓSIO SOBRE MATA CILIAR. Anais... Fundação Cargill, 1989. p.25-42.

LIMA, W.P. Relações hidrológicas em matas ciliares. In: HENRY, R. (Ed.). Ecótonos nas Interfaces dos Ecossitemas Aquáticos. São Carlos: RiMa Editora, 2003.p.293-300.

LIMA, W.P.; ZAKIA, M.J.B. Hidrologia de matas ciliares. In: RODRIGUES, R.R., LEITÃO FILHO, H.F. (Eds.) Matas ciliares: conservação e recuperação. EDUSP/FAPESP, 2000.p.33-44.

MORAES, J.M. Aplicação do TOPMODEL na bacia do ria Corumbataí. 1998. Relatório de Pós-Doutorado, FAPESP/CENA.

PIECE, R.S. Evidence of overland flow on forest watershed. In: International Symposium on Forest Hydrology. Pergamon Press, 1967.p.247-254.

QUINN, P.F.; BEVEN, K.J.; LAMB, R. The In $(a / \tan B)$ index: how to calculate it and how to use it in TOPMODEL framework. Hydrologycal Process, v.9,p.161-182, 1995.

SAULNIER, G.M. Information pedologique spatialisee et traitments topographiques ameliores dons la modelisation hydrologique par TOPMODEL. 1996.288 f. Tese (Doutorado)INPG, Grenoble, France.

ZAKIA, M.J.B. Identificação e caracterização da zona ripária em uma microbacia experimental: implicações no manejo de bacias hidrográficas e na recomposição de florestas. 1998.98 f. Tese (Doutorado) - Escola de Engenharia de São Carlos, Universidade de São Paulo, São Carlos, SP. 